\title{
Determination of picomolar levels of methylmercury complexes with low molecular mass thiols by liquid chromatography tandem mass spectrometry and online preconcentration
}

\author{
Van Liem-Nguyen ${ }^{1} \cdot$ Hoang-Tung Nguyen-Ngoc ${ }^{2} \cdot$ Gbotemi A. Adediran ${ }^{2} \cdot$ Erik Björn $^{2}$ \\ Received: 15 November 2019 / Revised: 23 December 2019 / Accepted: 6 January 2020 / Published online: 16 January 2020 \\ (C) The Author(s) 2020
}

\begin{abstract}
Methylmercury $(\mathrm{MeHg})$ is one of the most potent neurotoxins. It is produced in nature through the methylation of inorganic divalent mercury $\left(\mathrm{Hg}^{\mathrm{II}}\right)$ by phylogenetically diverse anaerobic microbes. The mechanistic understanding of the processes that govern the extent of bacterial export of $\mathrm{MeHg}$, its bioaccumulation, and bio-toxicity depends on accurate quantification of its species, especially its complexation with low molecular mass thiols; organometallic complexes that are difficult to detect and measure in natural conditions. Here, we report the development of a novel analytical method based on liquid chromatography tandem mass spectrometry (LC-MS/MS) to determine $13 \mathrm{MeHg}$ complexes with important thiol compounds which have been observed in the environment and in biological systems. By using online preconcentration via solid phase extraction (SPE), the method offers picomolar (12-530 pM) detection limits, the lowest reported so far for the determination of MeHg compounds. Among three different SPE materials, a weak cation exchange phase showed the best efficiency at a low $\mathrm{pH}$ of 2.5. We further report the presence of $\mathrm{MeHg}$-cysteine, MeHg-cysteamine, MeHg-penicillamine, MeHg-cysteinylglycine, and $\mathrm{MeHg}$ glutamylcysteine as the predominant $\mathrm{MeHg}$-thiol complexes in the extracellular milieu of an important $\mathrm{Hg}^{\mathrm{II}}$ methylating bacterium, Geobacter sulfurreducens PCA, exposed to $100 \mathrm{nM}$ of $\mathrm{Hg}^{\mathrm{II}}$.
\end{abstract}

Keywords Methylmercury-thiol complex · Low molecular mass thiols · Liquid chromatography tandem mass spectrometry . Online preconcentration

\section{Introduction}

Methylmercury (MeHg) is ingested by humans mainly via rice and fish consumption $[1,2]$ and can damage the central nervous system and kidney and is especially dangerous for fetuses and infants [3]. The MeHg ion $\left(\mathrm{CH}_{3} \mathrm{Hg}^{+}\right)$ has a strong affinity for soft base ligands, especially inorganic and organic reduced sulfur compounds (sulfide and

Electronic supplementary material The online version of this article (https://doi.org/10.1007/s00216-020-02389-y) contains supplementary material, which is available to authorized users.

Erik Björn

erik.bjorn@umu.se

1 Laboratory of Advanced Materials Chemistry, Advanced Institute of Materials Science, Ton Duc Thang University, 19 Nguyen Huu Tho Street, Tan Phong Ward, District 7, Ho Chi Minh City, Vietnam

2 Department of Chemistry, Umeå University, 90187 Umeå, Sweden thiols, respectively) [4], and the chemical speciation of $\mathrm{MeHg}$ in environmental and biological systems is largely dominated by complexes with sulfide, and low or high molecular mass thiols [4-6]. Low molecular mass (LMM) thiols are important in biological processes due to the complexation ability of the thiol functional group with metal ions and subsequent bio-transformations between the thiols and disulfides through redox reactions mediated by enzymatic activities [7,8]. LMM thiols are directly synthesized by living organisms and/or indirectly formed through the reaction of sulfide with unsaturated natural organic matter in the environment [9-11]. Such thiol compounds are typically found at $\mathrm{nM}$ to $\mu \mathrm{M}$ concentrations in the environments, but they have also been found in $\mathrm{mM}$ concentrations [12-14]. Even when present at low concentrations, LMM thiols play important roles in $\mathrm{MeHg}$ speciation [5, 13].

Intracellular methylation of inorganic divalent mercury $\left(\mathrm{Hg}^{\mathrm{II}}\right)$ by widely spread anaerobic microbes carrying the 
$h g c A$ and $h g c B$ genes is generally being accepted as the main source of $\mathrm{MeHg}$ formation and release into the environment [15-19]. Significant increases in the $\mathrm{Hg}^{\mathrm{II}}$ methylation rate have been reported for bacteria culture assays amended with specific LMM thiols [20, 21] and subsequent cellular export of $\mathrm{MeHg}$ has been observed to be facilitated by addition of cysteine [22]. In a recent study, a characterization of the extracellular milieu of Geobacter sulfurreducens $P C A$, an iron reducing bacterium capable of $\mathrm{Hg}^{\mathrm{II}}$ methylation, revealed metabolically active biosynthesis of various LMM thiol compounds [11]. Despite the scientific evidences of the important roles of LMM thiols for $\mathrm{MeHg}$ cycling, the measurement of specific $\mathrm{MeHg}$ thiol complexes has been hampered by constraints in analytical measurement techniques, and the behavior of specific $\mathrm{MeHg}$-thiol in the environment as well as in biological systems remains poorly investigated.

Methylmercury and particularly $\mathrm{Hg}^{2+}$ have a strong affinity for reduced sulfur group in thiol compounds. The typical ranges of stability constants $(\log \mathrm{K})$ for the formation of $\mathrm{MeHg}$-thiol and $\mathrm{Hg}(\text { thiol })_{2}$ complexes are 16.0 17.5 and 34.6-42.1, respectively [23, 24]. Fast reaction kinetics between $\mathrm{MeHg}$ or $\mathrm{Hg}^{2+}$ and thiols have been reported using nuclear magnetic resonance spectroscopy [24-26]. Synchrotron X-ray fluorescence mapping has been combined with $\mathrm{Hg} \mathrm{L}_{\mathrm{III}} \mathrm{X}$-ray absorption near-edge spectroscopy to constrain the localization and speciation of $\mathrm{Hg}$ and $\mathrm{MeHg}$ in rice grain. It was shown that $\mathrm{MeHg}$ is present in rice bran predominantly as $\mathrm{MeHg}$ bound to cysteine. The $\mathrm{MeHg}$-cysteine complex behaves like a mobile nutrient and is actively transported to the endosperm of rice grains during seed ripening [27]. The binding of $\mathrm{MeHg}$ to cysteine has also been demonstrated in fish muscle [28]. Furthermore, addition of thiols e.g., cysteine, has been shown to either enhance or suppress $\mathrm{MeHg}$ formation in bacteria culture assays depending on the added concentration $[20,29]$.

Previous attempts to elucidate reactions and processes of MeHg-thiols have mainly been based on thermodynamic modeling of the concentrations of such complexes [5]. Relying only upon thermodynamic modeling is however limited by uncertainties in stability constants and by potential kinetic constraints [24, 30]. Most analytical methods in mercury biogeochemistry research have been developed for the determination of the concentration of total mercury $(\mathrm{Hg})$, elemental $\mathrm{Hg}\left(\mathrm{Hg}^{0}\right)$, or total $\mathrm{MeHg}$ (i.e., sum concentration of all $\mathrm{MeHg}$ species), with very few being dedicated to direct measurement of individual $\mathrm{MeHg}$ species [31-33]. Gas chromatography (GC) has been widely used as separation technique due to its advantages of high peak resolution and short analysis time. However, ionic metal complexes must typically be derivatized prior to separation in which case information of metal complex speciation is lost. Liquid chromatography (LC) is an alternative technique with the possibility of maintaining metal-ligand information [31]. Krupp et al. [34] reported a method for determination of $\mathrm{MeHg}$ and $\mathrm{Hg}^{\mathrm{II}}$ complexes with cysteine (Cys) and glutathione (GSH) by LC electrospray ionization mass spectrometry (ESI-MS) and LC combined with inductively coupled plasma mass spectrometry (ICPMS). The method focused on complex identification whereas limits of detection (LODs) were not reported and losses of complexes during the determination was observed but not resolved. Bouchet and Björn [35] reported an analytical method to directly measure specific $\mathrm{MeHg}$-thiol complexes based on LCICPMS. Although the method was successful in measuring some $\mathrm{MeHg}$-thiol complexes with relatively low LODs ranging from 0.6 to $7.4 \mathrm{nM}$, it suffered from limited selectivity due to retention overlaps particularly for highly hydrophilic complexes [35]. The sensitivity of LC-ICPMS methods is generally high with respect to the $\mathrm{Hg}$ signal but different $\mathrm{MeHg}$ complexes are identified by chromatographic retention time only. This causes a relatively large risk for peak overlaps and misidentification in samples with many thiol compounds, in particular if the sample also contains a substantial concentration of $\mathrm{Hg}^{\mathrm{II}}$ forming $\mathrm{Hg}^{\mathrm{II}}$-thiol complexes $[12,35]$. In bacteria culture and environmental systems, many different LMM thiol compound are often present $[5,11]$ and the development of a highly selective and more robust method is therefore essential to characterize $\mathrm{MeHg}$-thiol complexes at concentrations relevant for culture systems with $\mathrm{Hg}^{\mathrm{II}}$ methylating bacteria and for the environment.

In this study, we present a novel methodology for the determination of a comparatively large number of $\mathrm{MeHg}$ complexes (13 complexes) with LMM thiol ligands which has been frequently found in bacteria culture assays and in terrestrial and aquatic ecosystems [5, 11, 12, 21, 35]. The method is based on LC coupled with ESI triple quadrupole tandem mass spectrometry (ESI-MS/MS) with selective reaction monitoring (SRM) detection mode. The identification of the complexes relies on (i) the specific retention time on the LC column and (ii) parental mass and product ions with optimized fragmentation condition for each complex. Combined with online preconcentration by solid phase extraction (SPE), the method offers LODs at the pM level for all investigated complexes, which is the lowest LODs reported up to date for $\mathrm{MeHg}$ complexes. The effect of different SPE materials, $\mathrm{pH}$, and sample matrix composition on the recovery of the complexes were investigated and optimized. The stability over time of the complexes was also investigated at different storage temperature. The optimized method was then applied to characterize MeHg-thiol complexes in the extracellular milieu of metabolically active G. sulfurreducens 
$P C A$, one of the most studied sub-surface $\mathrm{Hg}^{\mathrm{II}}$ methylating bacteria in nature, amended with $100 \mathrm{nM} \mathrm{HgCl}{ }_{2}$.

\section{Experimental}

\section{Chemicals and reagents}

Methylmercury chloride $(\mathrm{MeHgCl})$ was purchased from Sigma-Aldrich (PESTANAL analytical grade, $\geq 98 \%$ ). All low molecular mass (LMM) thiol compounds were also purchased from Sigma-Aldrich; their structures and abbreviations used throughout this manuscript are given in the Electronic Supplementary Material (ESM), Fig. S1. Formic acid (FA) was from Fluka, and methanol $(\mathrm{MeOH})$ from Merck. Ultrapure Milli-Q water (> $18 \mathrm{M} \Omega . \mathrm{cm}$ ) was obtained through a Milli-Q Advantage A10 Ultrapure Water Purification System (Merck Millipore). Stock solutions of MeHg $(4.0 \mathrm{mM})$ were prepared in $0.1 \mathrm{M} \mathrm{HCl}$ and preserved at + $4{ }^{\circ} \mathrm{C}$, and the $\mathrm{MeHg}$ concentration was verified by combustion atomic absorption spectrometry measurements (Direct Mercury Analyzer DMA-80, Milestone). Thiol solutions $(10 \mathrm{mM})$ were freshly prepared individually with deoxygenated Milli-Q water (purging $1 \mathrm{~h}$ with $300 \mathrm{~mL} \mathrm{~min}^{-1} \mathrm{~N}_{2}$ inside a glove box) under $\mathrm{N}_{2}$ atmosphere in a glove box. A 10-ml standard mixture consisting of $100 \mu \mathrm{M}$ of each LMM thiol (13 thiols) was prepared by pipetting $100 \mu \mathrm{l}$ of each LMM thiol solution $(10 \mathrm{mM})$ and diluting with $8.7 \mathrm{ml}$ deoxygenated Milli-Q water. In a 15-ml falcon tube (polypropylene), a solution containing $10 \mu \mathrm{M}$ of each $\mathrm{MeHg}$-thiol complex was prepared by addition of $1 \mathrm{ml}$ of the mixed LMM thiols standard (100 $\mu \mathrm{M}$ of each thiol compound) with $8.3 \mathrm{ml}$ deoxygenated Milli-Q water and $0.7 \mathrm{ml}$ of MeHg stock solution $(4.0 \mathrm{mM})$. The solution was rotated for $3 \mathrm{~h}$ prior to further dilution by $0.1 \%$ formic acid in deoxygenated Milli-Q water $(\mathrm{pH}=2.7)$.

Geobacter sulfurreducens subsp. sulfurreducens PCA (American Type Culture Collection 51,573) was purchased from DSMZ. It was grown under $\mathrm{N}_{2}$ atmosphere at $28{ }^{\circ} \mathrm{C}$ and $\mathrm{pH} 6.8$ in a defined growth medium as fully described by Schaefer et al. [20]. An experimental assay buffer typically used for $\mathrm{Hg}^{\mathrm{II}}$ methylation experiment with $\mathrm{G}$. sulfurreducens was adopted for this study [20,21]. This buffer is composed of 2.1 MOPS, $0.03 \mathrm{MgSO}_{4} .7 \mathrm{H}_{2} \mathrm{O}, 0.1 \mathrm{KCl}, 0.01 \mathrm{NaCl}$, $\mathrm{NaH}_{2} \mathrm{PO}_{4} \cdot \mathrm{H}_{2} \mathrm{O}, 0.005 \mathrm{NH}_{4} \mathrm{Cl}, 0.082 \mathrm{CH}_{3} \mathrm{COONa}, 0.001$ resazurin, all concentrations given in $\mathrm{g} / \mathrm{L}$, and $1 \mathrm{mM}$ fumarate with $\mathrm{pH}$ adjusted to 6.8 with $10 \mathrm{M} \mathrm{NaOH}$ solution.

\section{Mass spectrometry and online preconcentration instrumentation}

The mass spectrometry instrumentation setup consisted of a PAL HTC autosampler (CTC Analytics AG, Zwingen,
Switzerland) with a cooled tray $\left(+5^{\circ} \mathrm{C}\right)$ connected to a Surveyor and an Accela LC-pump (Thermo FisherScientific, San Jose, CA, USA) dedicated to an online SPE cartridge and the analytical LC column, respectively, and a TSQ Quantum Ultra electrospray ionization triple quadrupole mass spectrometer instrument (Thermo Fisher Scientific, San Jose, CA, USA). Peek tubing ( $\varnothing 0.13 \mathrm{~mm}$, Restek) was used to connect the different instrumental parts.

The general operating conditions for the instrument are given in Table 1. The fragmentation of each $\mathrm{MeHg}$-thiol complex was studied by direct infusion to the TSQ Quantum Ultra instrument of solutions containing $10 \mu \mathrm{M}$ of individual complexes using a flow rate of $25 \mu \mathrm{l} \mathrm{min}{ }^{-1}$ combined with a $250 \mu \mathrm{min}^{-1}$ auxiliary flow rate of 50:50 $\mathrm{MeHg}: \mathrm{H}_{2} \mathrm{O}$ with $0.1 \%$ FA. Full scan spectra of the complexes were recorded in both negative and positive ionization mode and parental masses of the complexes were identified based on $\mathrm{Hg}$ isotope pattern and the matching to theoretical masses of the complexes. Tube lens voltages and collision energy were optimized and thereafter set up individually for each complex in the selective reaction monitoring (SRM) method.

The sample loading procedure for online SPE preconcentration was previously described by LiemNguyen et al. [12]. Briefly, $1 \mathrm{~mL}$ of sample was loaded onto an online SPE cartridge with a switching-column array made up of a 6-port and a 10-port switching valve manufactured by Valco Instruments Co. The elution gradients used for the analytical columns with and without SPE are shown in Table S1 (see ESM). The recovery of $\mathrm{MeHg}$-thiol complexes on different SPE materials was investigated based on their molecular structure which frequently contain alkyl, amino $\left(\mathrm{NH}_{2}\right)$ and carboxylic $(\mathrm{COOH})$ functional groups. The $\mathrm{MeHg}$-thiol complexes have weak acid or base properties depending on $\mathrm{pH}$ of the solution. Thus, three different SPE cartridges of dimensions $2.1 \times 20 \mathrm{~mm}, 15 \mu \mathrm{m}$ were investigated at different pH: Hydrophilic-Lipophilic-Balanced (HLB) Oasis, Weak-Cation-Exchange (WCX) Oasis, and Weak-AnionExchange (WAX) Oasis, Water Scientific.

\section{Figures of merit determinations}

The recovery of the online SPE procedure was calculated by comparing the analyte signal intensities of the complexes with SPE $(0.1 \mu \mathrm{M}$ and $1.0 \mathrm{ml}$ injection $)$ and without SPE $(10 \mu \mathrm{M}$ and $10 \mu \mathrm{l}$ injection, i.e., direct injection onto the analytical column). Recovery was determined for both Milli-Q water with $0.1 \%$ FA and bacteria incubation media matrices. The LODs were calculated as 3 times the standard deviation (SD, $n=11)$ of the peak areas for Milli-Q water with $0.1 \%$ FA blank solutions divided by the sensitivity on a peak area per concentration basis (achieved from calibration curves). The peak area of each 
Table 1 Operating parameters for the instrument

\begin{tabular}{ll}
\hline Mass spectrometry & Thermo Scientific TSQ Quantum Ultra \\
Ion source & Heated electrospray ionization \\
Mode & Negative/positive \\
Sheath/auxiliary gas flow & $60 / 25$ (arbitrary units) \\
Collision gas & $1.5 \mathrm{ml} \mathrm{min}{ }^{-1}$ (argon) \\
Electrospray voltage & $3.5 \mathrm{kV}$ \\
Capillary/vaporizer temperature & $325 / 225^{\circ} \mathrm{C}$ \\
Scan range $(m / z)$ & $200-1000$ \\
HPLC column & Phenomenex, Kinetic Biphenyl $(3.0 \times 150 \mathrm{~mm}, 5 \mu \mathrm{m})$ \\
SPE cartridge & Water, Oasis WCX $(2.1 \times 20 \mathrm{~mm}, 15 \mu \mathrm{m})$ \\
Mobile phase & $0.1 \% \mathrm{FA}$ in water/MeOH $(20-90 \%)$ \\
Injection volumes & $10 \mu l$ or $1 \mathrm{ml}$ \\
\hline
\end{tabular}

complex was the combined signal of the two product ions. The calibration curves were established with mixtures of the $\mathrm{MeHg}$-thiol complexes with concentrations ranging from 1 to $50 \mathrm{nM}$ of each complex in either MQ water or bacteria incubation medium. The method's repeatability was evaluated with triplicate injections of standards. The complexes' stability over time (30 days) at different storage temperature (room temperature $\left(+22{ }^{\circ} \mathrm{C}\right),+4{ }^{\circ} \mathrm{C}$ and $-20^{\circ} \mathrm{C}$ ) was investigated by preparing batches of mixed solutions containing $100 \mathrm{nM}$ of each complex in $0.1 \% \mathrm{FA}$ in 15-ml polypropylene falcon tubes. The samples with different storing temperature were all prepared on day 1 and sacrificed for analyses at regular time intervals during 30 days. The drift in instrument sensitivity during the 30 day investigation was corrected for by normalization of the peak areas of test samples to the corresponding peak areas of freshly prepared $\mathrm{MeHg}-$ thiol standards (100 nM each).

\section{Bacteria culture and incubation}

Bacteria cells were harvested from the growth medium by centrifugation at mid-exponential phase under anaerobic condition. The harvested cells were then washed three times with $50 \mathrm{ml}$ of assay buffer to ensure all adhering nutrients from the growth medium were washed off before the cells were resuspended in assay buffer. The presence of $\mathrm{MeHg}$-thiol complexes was investigated following the methylation of $\mathrm{Hg}^{\mathrm{II}}$ in assays with $100 \mathrm{nM} \mathrm{HgCl}_{2}$ as described in Schaefer et al. [21] using a final assay of $\sim 10^{8}$ cell $\mathrm{ml}^{-1}$, a bacterial population density typical of pure culture methylation experiments with G. sulfurreducens [20, 21, 36]. It is noteworthy that the methylation assay remained colorless throughout the 6- and 48-h incubation period at $30{ }^{\circ} \mathrm{C}$, which indicated that the bacteria were not physiologically stressed and that the assays remained anaerobic. After 6 or $48 \mathrm{~h}$ of incubation, the assay medium was filtered through $0.2-\mu \mathrm{m}$ syringe filters and the $\mathrm{pH}$ of the
Table 2 Product ions obtained from each $\mathrm{MeHg}$-thiol complex with the triple quadrupole mass spectrometer instrument (Thermo scientific TSQ Quantum Ultra). The product ions are sorted from high to low signal intensity (left to right) normalized to the signal of the fragment with highest intensity. Italic font indicates the two most frequently obtained product ions. The quantification method was set for the parental mass and the two most sensitive product ions of each complex; the third product ion was used for qualitative analysis

\begin{tabular}{llll}
\hline Complexes & $\begin{array}{l}\text { Parental } \\
\text { mass }(\mathrm{m} / \mathrm{z})\end{array}$ & $\begin{array}{l}\text { Tube } \\
\text { lens }(\mathrm{V})\end{array}$ & $\begin{array}{l}\text { Product ions }(\mathrm{m} / \mathrm{z})(\text { relative intensity } \%, \text { and optimum collision } \\
\text { energy }(\mathrm{V}) \text { are given in parenthesis) }\end{array}$ \\
\hline MeHg-2MPA & 320.9 & -92.4 & $249.1(90 \%, 20), 277.4(5 \%, 10), 243.2(2 \%, 79)$ \\
MeHg-SULF & 356.9 & -75.6 & $249.1(100 \%, 23), 233.8(18 \%, 41), 80.3(13 \%, 37)$ \\
MeHg-SUC & 364.9 & -67.3 & $249.1(95 \%, 23), 347.1(23 \%, 14), 320.9(10 \%, 5)$ \\
MeHg-Cyst & 293.9 & 77.8 & $277.1(100 \%, 6), 217.1(33 \%, 24), 234.1(14 \%, 6)$ \\
MeHg-Glyc & 324.9 & 72.8 & $307.1(90 \%, 5), 217.1(33 \%, 35), 263.1(30 \%, 11)$ \\
MeHg-Cys & 337.9 & 98.6 & $321.1(100 \%, 6), 217.1(28 \%, 32), 234.1(19 \%, 10)$ \\
MeHg-HCys & 351.9 & 91.4 & $335.1(100 \%, 10), 306.1(90 \%, 12), 56.2(70 \% .18)$ \\
MeHg-Pen & 365.9 & 81.8 & $349.1(100 \%, 7), 217.1(30 \%, 23), 305.1(25 \%, 23)$ \\
MeHg-NACCys & 379.9 & 84.3 & $362.1(90 \%, 6), 321.0(26 \%, 14), 56.2(15 \%, 41)$ \\
MeHg-CysGly & 394.9 & 90.0 & $378.1(100 \%, 10), 217.1(15 \%, 35), 321.0(12 \%, 16)$ \\
MeHg-NACPen & 407.9 & 90.0 & $390.2(100 \%, 6), 70.4(45 \%, 33), 349.1(10 \%, 13)$ \\
MeHg-GluCys & 466.9 & 113.1 & $321.0(100 \%, 16), 217.1(19 \%, 39), 346.2(15 \%, 17)$ \\
MeHg-GSH & 524.0 & 109.1 & $378.1(100 \%, 16), 395.2(25 \%, 11), 345.1(10 \%, 22)$
\end{tabular}


Fig. 1 Typical LC-ESI-MS/MS chromatograms for parental ion measurements of the $13 \mathrm{MeHg}-$ thiol complexes (100 nM each, $\mathrm{pH}=2.7)$ using a Phenomenex Biphenyl Kinetic $(3.0 \times 150 \mathrm{~mm}$, $5 \mu \mathrm{m})$ reversed-phase column fitted with a phenyl guard column $(3.0 \times 4.0 \mathrm{~mm}, 5 \mu \mathrm{m})$, after online preconcentration on a WCX SPE column with $1 \mathrm{~mL}$ injection volume

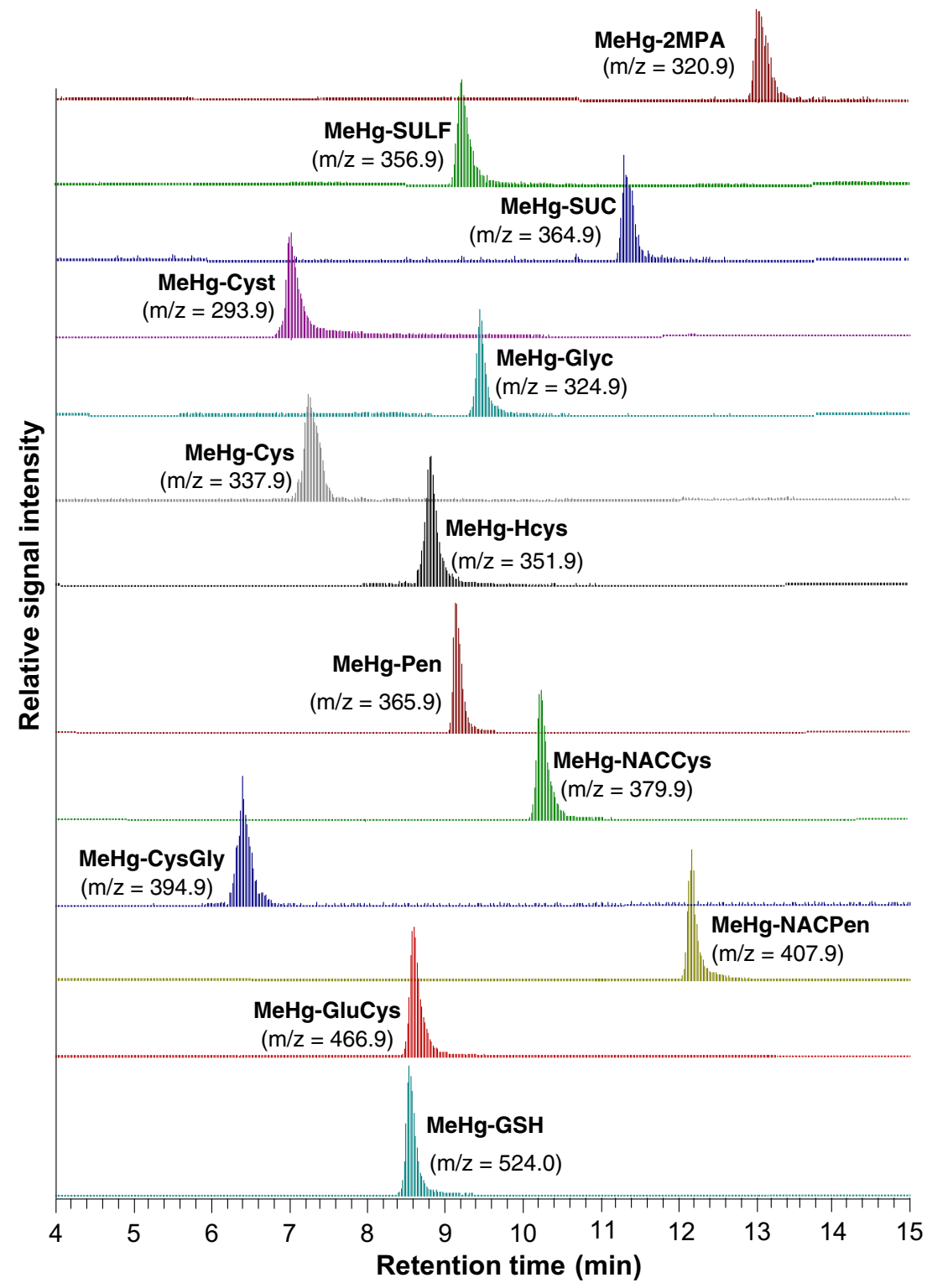

filtrate was adjusted to 2.7 by concentrated $\mathrm{H}_{2} \mathrm{SO}_{4}$ prior to analysis.

\section{Results and discussion}

\section{Fragmentation of the MeHg-thiol complexes}

The fragmentation of each $\mathrm{MeHg}$-thiol complex was first investigated by directly introducing standard solutions to the mass spectrometer (without LC) in both negative and positive ESI mode with a mass scan ranging from 200 to $1000 \mathrm{~m} / \mathrm{z}$. The spectra of representative complexes are given in Fig. S2 (see ESM) and product ions obtained from each $\mathrm{MeHg}$-thiol complex with the triple quadrupole mass spectrometer instrument is presented in Table 2. After the parental mass and product ions of each investigated complex were established, the selected reaction monitoring (SRM) mode was applied for quantification of the complexes. The SRM method was set to target the precursor ion and the two most abundant product ions for each complex using their respective optimal tube lens voltages and collision energies. The peak area signals corresponding to the transition of the parental ion to the two product ions of each complex were recorded and used for quantification of the $\mathrm{MeHg}$-thiol complexes. For complex verification in the test solutions and real samples the peak area signal ratio of the two product ions was compared with the corresponding ratio of pure standard solutions in tune mode.

A typical LC-ESI-MS/MS chromatogram for the complexes is shown in Fig. 1. Among the 13 investigated $\mathrm{MeHg}$-thiol complexes, 3 complexes, i.e., MeHg-2MPA, $\mathrm{MeHg}-\mathrm{SUC}$, and MeHg-SULF, showed higher signal 
intensity in negative ESI mode whereas the other 10 complexes gave higher signal intensity in positive ionization mode. The presence of protonated amino groups $\left(-\mathrm{NH}_{3}{ }^{+}\right.$or $\mathrm{NH}_{2}{ }^{+}$) generates positive charges and high signal intensity of the complex in positive ionization mode. The structures of 2MPA, SUC and SULF do not contain amino groups but carboxylic groups $(-\mathrm{COOH})$ which provide a negative charge when deprotonated and thereby a higher intensity in negative mode (ESM Fig. S1). The parental mass of the complexes was confirmed based on the matching of the $\mathrm{Hg}$ isotope pattern and matching between their theoretical and measured molecular mass $(\mathrm{m} / \mathrm{z})$ corresponding to the ionization mode. The two fragments $m / z, 217\left(\mathrm{CH}_{3}-\mathrm{Hg}^{+}\right)$and $249\left(\mathrm{CH}_{3} \mathrm{Hg}-\mathrm{S}^{+}\right)$were the most commonly observed and were obtained for MeHg-Cyst, $\mathrm{MeHg}-\mathrm{Glyc}$, MeHg-Cys, MeHg-Pen, MeHg-CysGly and MeHg-GluCys, MeHg-2MPA, MeHg-SULF, and MeHgSUC. These 9 (of the 13) complexes thus produced common product ions specific for $\mathrm{MeHg}$-thiol complexes with preserved $\mathrm{CH}_{3}-\mathrm{Hg}$ or $\mathrm{CH}_{3} \mathrm{Hg}-\mathrm{S}$ bonds. A similar fragmentation transition was previously observed during the determination of LMM thiols by ESI-MS/MS using p-(Hydroxymercuri) Benzoate, a probe containing $\mathrm{Hg}$, as a derivatization reagent [12].

\section{Online SPE preconcentration and matrix effect}

Three different Waters Oasis SPE cartridges (WCX, WAX, HLB) with the same structure basis were investigated [37]. Among those SPE cartridges, the HLB is the "base material" which offers both hydrophilic and lipophilic interactions through 2-pyrrolidone, and phenyl and alkyl functional groups. The WCX and WAX cartridges are modified versions

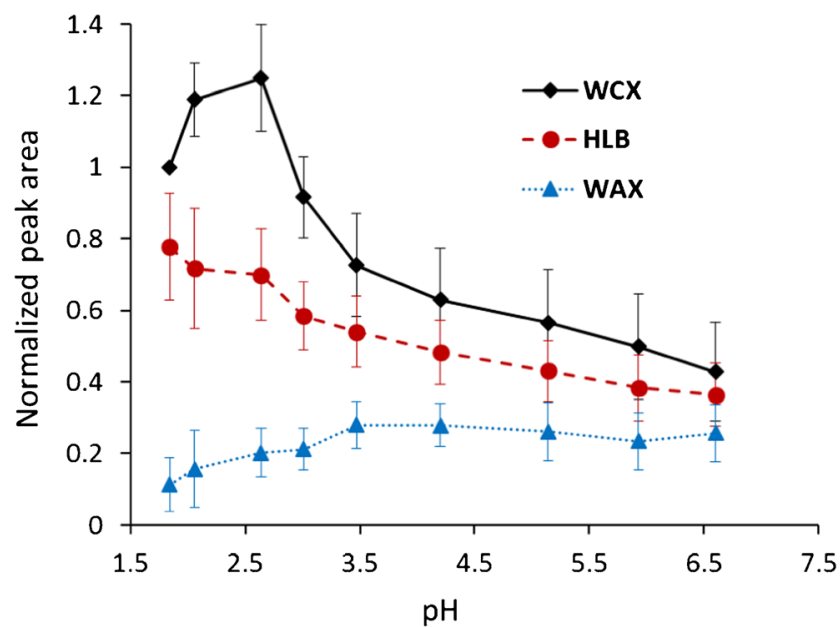

Fig. 2 Average normalized peak area of MeHg-thiol complexes $(100 \mathrm{nM}$ each) by SPE preconcentration using three different SPE phases (WCX, HLB, WAX). The peak areas are normalized to the ones obtained at $\mathrm{pH}$ of 1.84 with the WCX cartridge for each complex. The samples were prepared in $0.1 \%$ FA Milli-Q water and $\mathrm{pH}$ was adjusted by varying additions of $1 \mathrm{M}$ of $\mathrm{NaOH}$ or $\mathrm{H}_{2} \mathrm{SO}_{4}$. The error bars represent confidence intervals $(p=0.05, n=26)$ for the 13 investigated complexes of the HLB with addition of extra carboxylic and diamino functional groups, respectively. The results showed that, in general, the WCX cartridge offered highest retention efficiency, on average 1.5-fold and 4-fold higher than the HLB and WAX, respectively, at the corresponding optimal $\mathrm{pH}$ for each SPE cartridge. The optimal $\mathrm{pH}$ range for the WCX cartridge was between 2.2 and 2.8 (Fig. 2). This could be explained by the fact that at $\mathrm{pH} 2.2$ to 2.8 , the carboxylic group of the WCX SPE and the amino group of MeHg-thiol complexes will be present as protonated forms, i.e., $-\mathrm{COOH}(\mathrm{pKa} \sim 5)$ and $\mathrm{NH}_{3}{ }^{+}$(pKa $=8$ to 11$)$, respectively. The hydrogen bonding and polar interaction between the $-\mathrm{COOH}$ and $-\mathrm{NH}_{3}{ }^{+}$functional groups enhance the retention of the complexes on the WCX cartridge. For the WAX cartridge, at a low $\mathrm{pH}(\mathrm{pH}<3)$ repulsive forces appear between the protonated positively charged diamino group of WAX (pKa $\sim 6$ ) and the amino group of the complexes. The recovery of the complexes on the WAX cartridge increased with $\mathrm{pH}$ which can be explained by a deprotonation of the $-\mathrm{COOH}(\mathrm{pKa}=2$ to 5) groups of the $\mathrm{MeHg}$-thiol complexes. Our initial results from offline SPE experiments demonstrated a strong retention of the investigated complexes (MeHg-Cys and MeHg-Pen) on a strong cation exchange cartridge (MCX, Water Oasis). However, a very strong elute solution (100 $\mathrm{mM}$ ammonium acetate in acetone) was needed to elute the complexes out of the cartridge. The MCX cartridge is therefore difficult to apply with the online SPE and ESI-MS/MS system, because of the high salt concentration and organic solvent strength constrains, and the investigation with online MCX cartridge was thus terminated.

\section{MeHg-thiol complexes synthesis and preservation}

The $\mathrm{MeHg}$-thiol complexes were synthesized with an excess stoichiometry of $\mathrm{MeHg}$ (normally using a $\mathrm{MeHg}$ to thiol molar ratio of 2). The advantage of this procedure is that the mixed MeHg-thiol complexes standard (13 thiols) can be accurately prepared because $\mathrm{MeHg}$ is always available for complete reaction with all thiol ligands. The time needed for completing the reaction between $\mathrm{MeHg}$ and thiols was investigated. Figure $3 \mathrm{a}$ shows that when $\mathrm{MeHg}$ was mixed with thiol ligands at a molar ratio of $2: 1([\mathrm{MeHg}] /[$ thiol $]=2)$, the reaction for formation of the corresponding $\operatorname{MeHgSR}(\mathrm{aq}) \mathrm{com}$ plexes was close to steady-state after $1 \mathrm{~h}$. From 1 to $3 \mathrm{~h}$, the average signal of the complexes increased on average by approximately $12 \%$, but not statistically significant, and was followed by steady-state conditions at extended reaction times. Fast reactions of $\mathrm{MeHg}$ and $\mathrm{Hg}^{\mathrm{II}}$ with $\mathrm{LMM}$ thiols have been reported in previous studies, with the average life time of $\sim 30 \mathrm{~s}$ and $0.01 \mathrm{~s}$, respectively [24-26]. The MeHg to thiol molar ratio was varied from 1 to 5 (3-h reaction time), Fig. 3b, and the results indicated that with a molar ratio of 2 or higher the MeHg-thiol complexes' signal plateaued. Thus, a reaction 
Fig. 3 The average normalized peak area of 13 investigated $\mathrm{MeHg}$-thiol complexes in the optimization of complexes synthesis following reaction time (a) and $\mathrm{MeHg}$ to thiol molar ratios (b). The peak areas are normalized to the ones obtained at the reaction time of $1 \mathrm{~h}(\mathbf{a})$ and the $\mathrm{MeHg}$ to thiol molar ratio of 1 (b). The error bars represent confidence interval $(p=0.05, n=26)$ for 13 investigated complexes

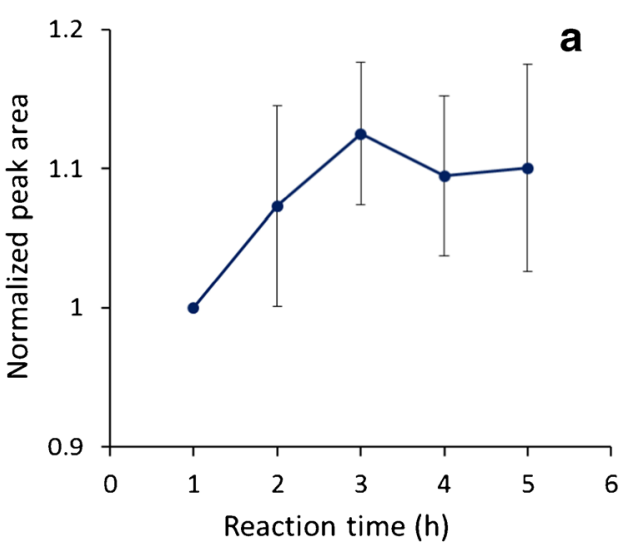

time of $3 \mathrm{~h}$ and a MeHg to thiol molar ratio of 2 was applied for further synthesis of the MeHg-thiol complexes.

It is well known that reduced thiol groups are highly reactive and unstable, and the stability of $\mathrm{MeHg}$-thiol complexes is not well-characterized. We analyzed series of sample batches stored in dark at different temperature (ambient (i.e., $\left.+22{ }^{\circ} \mathrm{C}\right),+4{ }^{\circ} \mathrm{C}$ and $-20^{\circ} \mathrm{C}$ ) in regular 15 -ml polypropylene falcon tubes. The results showed that all investigated complexes were stable for at least 2 weeks at all conditions, and MeHg-2MPA, MeHg-SUC, MeHg-SULF, MeHg-NACPen, and MeHg-GSH were stable for at least 30 days. Different temperatures did not significantly affect the complexes' stability as can be observed in Fig. S3 (see ESM). A previous study has shown that LMM thiols derivatized to $\mathrm{O}_{2} \mathrm{C}_{7} \mathrm{H}_{5} \mathrm{Hg}$-thiol complexes are stable for up to a month in most cases at $+4{ }^{\circ} \mathrm{C}$ and $-20{ }^{\circ} \mathrm{C}$ [12]. This indicates that metal ions (in this case $\mathrm{MeHg}$ ) efficiently stabilize the RSH group of LMM thiol compounds, reducing its reactivity for oxidation/degradation.

\section{Figures of merit}

Without using SPE preconcentration, the LODs for the $\mathrm{MeHg}$-thiol complexes ranged from 0.5 to $32 \mathrm{nM}$, which is comparable to previous methods using LC-ICPMS [35]. In combination with online SPE preconcentration, the method achieved the lowest LODs for the determination of $\mathrm{MeHg}-$ thiol complexes up to date with a range from 0.012 to $0.53 \mathrm{nM}$ and average of $0.16 \mathrm{nM}$ (Table 3). By using SPE preconcentration, the LODs were improved by on average a factor of 70 as compared to without SPE. This improvement was lower than the theoretical preconcentration factor (i.e., 100 ), which is explained by a non-quantitative recovery of the complexes (average 86\% recovery) and an increased signal to noise level. Overall, the LODs were lower for the complexes measured in positive ESI mode (average $0.12 \mathrm{nM}$ ) compared to the ones measured in negative ESI mode (average $0.34 \mathrm{nM})$ with the exception of MeHg-Glyc $(0.35 \mathrm{nM})$ and MeHg-HCys ( $0.42 \mathrm{nM}$ ) which had comparably high LOD despite being analyzed in positive mode (Table 3 ). The complexes analyzed in positive ESI showed about 15 -fold higher signal intensity compared to the ones analyzed in negative ESI; however, the noise level in the positive mode was about 4-fold higher.

The recoveries for the MeHg-thiol complexes when using the SPE preconcentration procedure compared to direct injection to the LC column was on average $86 \pm 8 \%$ (range 75 $102 \%)$ for a Milli-Q water matrix (0.1\% FA) and $78 \pm 8 \%$ (range 71-85\%) for the bacteria incubation assay medium ( $0.1 \%$ FA) (ESM Table S2). Therefore, about $10 \%$ and $20 \%$ of the complexes was lost during the preconcentration for Milli- Q water matrix and the bacteria incubation medium, respectively. The matric effects from the bacteria incubation assay medium on the quantification of the complexes were investigated by comparing signal to noise ratio $(\mathrm{S} / \mathrm{N})$ between Milli-Q water $(\mathrm{pH}=2.7)$ and the incubation medium $(\mathrm{pH}=$ 2.7) matrices containing $20 \mathrm{nM}$ of each MeHg-thiol complex. The results showed that the difference in $\mathrm{S} / \mathrm{N}$ between the two matrices was less than 30\% for MeHg-SUC, MeHg-Glyc, MeHg-Pen while the $\mathrm{S} / \mathrm{N}$ was reduced 2 to 8 folds for the other complexes. There were no significant differences in the signal intensities of the complexes in the two matrices; therefore, the reduced $\mathrm{S} / \mathrm{N}$ ratios were caused by an increase in the background level with the incubation medium. To minimize the effect of the medium composition and recovery of the LC column on the quantification of the complexes, calibration curves were established using the incubation media as matrix for the standard solutions in this case.

\section{Determination of MeHg-thiol complexes in G. sulfurreducens assay}

Adediran et al. recently reported biosynthesis and excretion of various LMM thiols in $G$. sulfurreducens bacteria cultures reaching up to about $120 \mathrm{nM}$ total thiol concentrations in the extracellular medium [11]. To demonstrate the potential of the developed method for the determination of MeHg-thiol complexes in the presence of bio-synthesized LMM thiols, $400 \mathrm{nM}$ of $\mathrm{MeHg}$ was added to filtered extracellular assay 
Table 3 Limits of detection (LODs) and analytical reproducibility (given as the relative standard deviation, RSD) achieved for each complex with optimized conditions without and with preconcentration by solid phase extraction (SPE)

\begin{tabular}{|c|c|c|c|c|c|}
\hline \multirow[t]{2}{*}{ Complexes } & \multirow[t]{2}{*}{ Ionization mode } & \multicolumn{2}{|l|}{ Without SPE } & \multicolumn{2}{|l|}{ With SPE } \\
\hline & & $\operatorname{LODs}^{\mathrm{a}}(\mathrm{nM})$ & $\operatorname{RSD}^{\mathrm{b}}(\%)$ & LODs (nM) & $\operatorname{RSD}(\%)$ \\
\hline MeHg-GSH & + & 0.50 & 2.8 & 0.012 & 3.3 \\
\hline MeHg-Pen & + & 0.75 & 5.2 & 0.015 & 11 \\
\hline MeHg-CysGly & + & 1.8 & 3.9 & 0.035 & 9.8 \\
\hline MeHg-NACCys & + & 3.4 & 4.5 & 0.038 & 6.4 \\
\hline MeHg-NACPen & + & 2.8 & 8.4 & 0.055 & 9.5 \\
\hline MeHg-GluCys & + & 2.5 & 7.3 & 0.065 & 10 \\
\hline MeHg-Cys & + & 6.0 & 5.7 & 0.087 & 12 \\
\hline MeHg-SULF & - & 17 & 8.7 & 0.14 & 9.6 \\
\hline MeHg-Cyst & + & 15 & 5.5 & 0.15 & 7.5 \\
\hline $\mathrm{MeHg}-2 \mathrm{MPA}$ & - & 20 & 6.7 & 0.25 & 8.3 \\
\hline MeHg-Glyc & + & 21 & 7.6 & 0.35 & 8.3 \\
\hline MeHg-HCys & + & 25 & 8.9 & 0.42 & 9.6 \\
\hline MeHg-SUC & - & 32 & 8.6 & 0.53 & 11 \\
\hline Average & & 11.4 & 6.4 & 0.16 & 8.9 \\
\hline
\end{tabular}

Milli-Q water $(0.1 \% \mathrm{FA})$ without SPE and with SPE preconcentration, respectively

${ }^{a}$ The LODs were determined as $3 \sigma$ of 11 blank replicates

${ }^{\mathrm{b}}$ The RSD were established with 5000 and $100 \mathrm{nM}$ standard solutions in medium collected after incubation for $6 \mathrm{~h}$ with live G. sulfurreducens cells. The samples were equilibrated in an $\mathrm{N}_{2}$ filled glove box for $3 \mathrm{~h}$ and the $\mathrm{pH}$ was then adjusted to 2.7 by sulfuric acid prior to analysis. Seven different $\mathrm{MeHg}$-thiol complexes were detected in the samples, MeHg-Cyst, MeHgCysGly, MeHg-Cys, MeHg-GluCys, MeHg-NACCys, $\mathrm{MeHg}-\mathrm{GSH}$, and MeHg-Pen with total concentration of $44 \mathrm{nM}$ (ESM Table S3). Thus, only about $10 \%$ of added $\mathrm{MeHg}$ was detected as complexes with the LMM thiols, which could be explained by a lower concentration of biosynthesis LMM thiols compared to the added MeHg and/or the reaction of $\mathrm{MeHg}$ with other thiols or functional groups in solution.

The method was then applied to identify and quantify extracellular $\mathrm{MeHg}$-thiol complexes at 6 and $48 \mathrm{~h}$ in active
G. sulfurreducens incubation assays amended with $100 \mathrm{nM}$ of $\mathrm{HgCl}_{2}$. The results in Table 4 show that, with the 6-h incubation, 4 complexes, MeHg-Cyst, MeHg-Cys, MeHg-Pen, and $\mathrm{MeHg}$-CysGly, were detected at concentrations ranging from 1.3 to $6.1 \mathrm{nM}$. For the 48 -h incubation, $6 \mathrm{MeHg}-\mathrm{LMM}$ thiols were detected including the 4 mentioned compounds and $\mathrm{MeHg}$-GluCys and $\mathrm{MeHg}$-GSH with concentrations ranging from 0.5 to $5.6 \mathrm{nM}$.

The stability constants of MeHg to LMM thiols are not well established and to gain further insight in the binding strength of different LMM thiols to $\mathrm{MeHg}$, separate determinations of the LMM thiol compounds that were synthesized and exported by the bacteria into the extracellular solution were also done using the methodology reported by Liem-Nguyen et al. [12]. Seven different LMM thiols were detected, Cys,
Table 4 Measured concentrations (nM) of extracellular $\mathrm{MeHg}$-thiol complexes and LMM thiol compounds in assay medium from G. sulfurreducens incubations with amendment of $100 \mathrm{nM}$ of $\mathrm{Hg}$. The cell density was $\sim 10^{8}$ cell $\mathrm{ml}^{-1}$ and constant during the incubation time

\begin{tabular}{|c|c|c|c|c|}
\hline \multirow[b]{2}{*}{ Complex } & \multicolumn{2}{|l|}{ 6-h incubation } & \multicolumn{2}{|l|}{ 48-h incubation } \\
\hline & $\begin{array}{l}\text { MeHg-thiol } \\
\text { complex (nM) }\end{array}$ & $\begin{array}{l}\text { Corresponding LMM } \\
\text { thiol compound (nM) }\end{array}$ & $\begin{array}{l}\text { MeHg-thiol } \\
\text { complex (nM) }\end{array}$ & $\begin{array}{l}\text { Corresponding LMM } \\
\text { thiol compound (nM) }\end{array}$ \\
\hline MeHg-Cys & $6.1 \pm 0.5$ & $30 \pm 6$ & $5.1 \pm 0.7$ & $33 \pm 5$ \\
\hline MeHg-Cyst & $5.2 \pm 0.7$ & $12 \pm 2$ & $5.6 \pm 0.4$ & $14 \pm 2$ \\
\hline MeHg-Pen & $3.2 \pm 0.3$ & $14 \pm 3$ & $3.0 \pm 0.5$ & $16 \pm 3$ \\
\hline MeHg-CysGly & $1.3 \pm 0.2$ & $5.3 \pm 1.5$ & $1.3 \pm 0.2$ & $7.3 \pm 1.5$ \\
\hline MeHg-GluCys & - & $2.6 \pm 1.3$ & $0.5 \pm 0.07$ & $6.2 \pm 1.6$ \\
\hline MeHg-NACCys & - & $1.8 \pm 0.6$ & - & $2.6 \pm 0.4$ \\
\hline MeHg-Hcys & - & $1.2 \pm 0.4$ & & $1.5 \pm 0.3$ \\
\hline Total & 15.8 & 67 & 16 & 81 \\
\hline
\end{tabular}


Cyst, Pen, CysGly, GluCys, NACCys, and HCys, with a total concentration of $67 \mathrm{nM}$ and $81 \mathrm{nM}$ for 6- and 48-h incubation, respectively (Table 4). A similar range of extracellular LMMthiol concentration was also reported by Adediran et al. for the same type of bacterium and similar bacteria density of $\sim 10^{8}$ cell $\mathrm{ml}^{-1}$ [11]. There was no significant difference $(t$ test, $p>0.05$ ) between the concentrations of MeHg-Cys and MeHg-Cyst complexes even though the total Cys concentration was about 2.5 times higher than the total Cyst concentration in the assay systems. This could be explained by a competition between $\mathrm{Hg}^{2+}$ and $\mathrm{MeHg}$ for LMM thiol ligands. $\mathrm{Hg}^{2+}$ has a stronger binding affinity to LMM thiols than $\mathrm{MeHg}$, and thus influences the formation of $\mathrm{MeHg}$-thiol complexes $[23,24]$. The stability constants for the formation of $\mathrm{Hg}(\mathrm{SR})_{2}$ complexes increase in the order $\mathrm{Hg}(\mathrm{GluCys})_{2}>$ $\mathrm{Hg}(\mathrm{Pen})_{2}>\mathrm{Hg}(\mathrm{Cys})_{2}>\mathrm{Hg}(\text { CysGly })_{2}>\mathrm{Hg}(\text { Cyst })_{2}$ [23]. The lower constant for $\mathrm{Hg}(\mathrm{Cyst})_{2}$ compared to $\mathrm{Hg}(\mathrm{Cys})_{2}$ can thus lead to a higher concentration of Cyst, compared to Cys, available for formation of complexes with $\mathrm{MeHg}$ when both thiols are present in the same concentration. In the system where only $\mathrm{MeHg}$ was added the concentration of MeHg-Cys was 1.6 times higher than MeHg-Cyst (ESM Table S3) which further supports the explanation of competition from $\mathrm{Hg}^{\mathrm{II}}$. The discrepancy in molar ratios of Cys/Cyst $=2.5$ and MeHg-Cys/ MeHg-Cyst $=1.6$ in the system without $\mathrm{Hg}^{\mathrm{II}}$ further implies a stronger binding affinity of MeHg to Cyst compared to Cys.

Even though NACCys and Hcys were detected their corresponding complexes with $\mathrm{MeHg}$ were not detected. This result could be explained by relatively low concentrations of these LMM thiols compared to the other ones yielding lower than LOD concentrations for the corresponding $\mathrm{MeHg}$ complexes. Overall, the results illustrate how the developed method is useful to investigate the stability of $\mathrm{MeHg}$-thiol complexes and direct measurements of MeHg-thiol complexes (and the corresponding LMM thiol) is important for accurate determinations of the thermodynamic stability constant of $\mathrm{MeHg}$-thiol complexes.

\section{Conclusion}

The developed method achieved excellent detection limits for a relatively large number of $\mathrm{MeHg}$-thiol complexes ranging from 12 to $530 \mathrm{pM}$. The method was carefully optimized and successfully applied to quantify various $\mathrm{MeHg}$-thiol complexes produced in bacteria incubation assays. With an amendment of $100 \mathrm{nM}$ of $\mathrm{Hg}^{\mathrm{II}}$, relevant to contaminated environment conditions, 5 different $\mathrm{MeHg}$-thiol complexes were quantified with concentrations ranging from 0.5 to $6.1 \mathrm{nM}$. This is the first time MeHg-thiol complexes are directly quantified in methylating bacteria cultures. The method offers a unique opportunity to improve our understanding of
MeHg biogeochemistry, especially bioaccumulation and biotoxicity processes in aquatic organisms and human organs.

Acknowledgements Open access funding provided by Umea University.

Funding information This work was financially supported by the Swedish Research Council via the project Sino-Swedish Mercury Management Research Framework - SMaReF (2013-6978) and the Kempe Foundations (JCK-1501, SMK-2745, SMK-1243).

\section{Compliance with ethical standards}

Conflict of interest The authors declare that they have no conflicts of interest.

Open Access This article is licensed under a Creative Commons Attribution 4.0 International License, which permits use, sharing, adaptation, distribution and reproduction in any medium or format, as long as you give appropriate credit to the original author(s) and the source, provide a link to the Creative Commons licence, and indicate if changes were made. The images or other third party material in this article are included in the article's Creative Commons licence, unless indicated otherwise in a credit line to the material. If material is not included in the article's Creative Commons licence and your intended use is not permitted by statutory regulation or exceeds the permitted use, you will need to obtain permission directly from the copyright holder. To view a copy of this licence, visit http://creativecommons.org/licenses/by/4.0/.

\section{References}

1. Zhang H, Feng X, Larssen T, Qiu G, Vogt RD. In inland China, rice, rather than fish, is the major pathway for methylmercury exposure. Environ Health Perspect. 2010;118(9):1183-A406.

2. U.S.E.P. Agency, National listing of fish advisories" (EPA fact sheet EPA-823-F-09-007). 2008.

3. Karagas MR, Choi AL, Oken E, Horvat M, Schoeny R, Kamai E, et al. Evidence on the human health effects of low-level methylmercury exposure. Environ Health Perspect. 2012;120(6):799-806.

4. Dyrssen D, Wedborg M. The sulfur-mercury(ii) system in naturalwaters. Water Air Soil Pollut. 1991;56:507-19.

5. Liem-Nguyen V, Skyllberg U, Björn E. Thermodynamic modeling of the solubility and chemical speciation of mercury and methylmercury driven by organic thiols and micromolar sulfide concentrations in boreal wetland soils. Environ Sci Technol. 2017;51(7): 3678-86.

6. Qian J, Skyllberg U, Frech W, Bleam WF, Bloom PR, Petit PE. Bonding of methyl mercury to reduced sulfur groups in soil and stream organic matter as determined by X-ray absorption spectroscopy and binding affinity studies. Geochim Cosmochim Acta. 2002;66(22):3873-85.

7. Meister A, Anderson ME. Glutathione. Annu Rev Biochem. 1983;52(1):711-60.

8. Gilbert HF. Redox control of enzyme activities by thiol/disulfide exchange. Methods Enzymol. 1984;107:330-51.

9. Moriarty-Craige SE, Jones DP. Extracellular thiols and thiol/ disulfide redox in metabolism. Annu Rev Nutr. 2004;24:481-509.

10. Vairavamurthy A, Mopper K. Geochemical formation of organosulphur compounds (thiols) by addition of H2S to sedimentary organic matter. Nature. 1987;329(6140):623-5.

11. Adediran GA, Liem-Nguyen V, Song Y, Schaefer JK, Skyllberg U, Björn E. Microbial biosynthesis of thiol compounds: implications 
for speciation, cellular uptake, and methylation of $\mathrm{Hg}$ (II). Environ Sci Technol. 2019;53(14):8187-96.

12. Liem-Nguyen V, Bouchet S, Björn E. Determination of subnanomolar levels of low molecular mass thiols in natural waters by liquid chromatography tandem mass spectrometry after derivatization with p-(hydroxymercuri) benzoate and online preconcentration. Anal Chem. 2014;87(2):1089-96.

13. Zhang J, Wang F, House JD, Page B. Thiols in wetland interstitial waters and their role in mercury and methylmercury speciation. Limnol Oceanogr. 2004;49(6):2276-86.

14. MacCrehan W, Shea D, Vairavamurthy M, Schoonen M, Eglinton $\mathrm{T}$, Luther $\mathrm{G}$, et al. Temporal relationship of thiols to inorganic sulfur compounds in anoxic Chesapeake Bay sediment porewater, ACS Symposium Series, vol. 612. Washington, DC: American Chemical Society; 1995. p. 294-310.

15. Compeau GC, Bartha R. Sulfate-reducing bacteria - principal methylators of mercury in anoxic estuarine sediment. Appl Environ Microbiol. 1985;50(2):498-502.

16. Kerin EJ, Gilmour CC, Roden E, Suzuki MT, Coates JD, Mason RP. Mercury methylation by dissimilatory iron-reducing bacteria. Appl Environ Microbiol. 2006;72(12):7919-21.

17. Hamelin S, Amyot M, Barkay T, Wang Y, Planas D. Methanogens: principal methylators of mercury in lake periphyton. Environ Sci Technol. 2011;45(18):7693-700.

18. Gilmour CC, Podar M, Bullock AL, Graham AM, Brown SD, Somenahally AC, et al. Mercury methylation by novel microorganisms from new environments. Environ Sci Technol. 2013;47(20): 11810-20.

19. Parks JM, Johs A, Podar M, Bridou R, Hurt RA, Smith SD. Tomanicek SJ, Qian Y, Brown SD, Brandt CC. The genetic basis for bacterial mercury methylation. Science 2013; 339(6125): 13321335 .

20. Schaefer JK, Morel FMM. High methylation rates of mercury bound to cysteine by Geobacter sulfurreducens. Nat Geosci. 2009;2(2):123-6.

21. Schaefer JK, Rocks SS, Zheng W, Liang LY, Gu BH, Morel FMM. Active transport, substrate specificity, and methylation of $\mathrm{Hg}(\mathrm{II})$ in anaerobic bacteria. Proc Natl Acad Sci U S A. 2011;108(21):87149.

22. Lin $\mathrm{H}, \mathrm{Lu} \mathrm{X}$, Liang L, Gu B. Thiol-facilitated cell export and desorption of methylmercury by anaerobic bacteria. Environ Sci Technol Lett. 2015;2(10):292-6.

23. Liem-Nguyen V, Skyllberg U, Nam K, Björn E. Thermodynamic stability of mercury (II) complexes formed with environmentally relevant low-molecular-mass thiols studied by competing ligand exchange and density functional theory. Environ Chem. 2017;14(4):243-53.

24. Reid RS, Rabenstein DL. Nuclear magnetic resonance studies of the solution chemistry of metal complexes. XVII. Formation constants for the complexation of methylmercury by sulfhydrylcontaining amino acids and related molecules. Can J Chem. 1981;59(10):1505-14.
25. Pei KL, Sooriyaarachchi M, Sherrell DA, George GN, Gailer J. Probing the coordination behavior of $\mathrm{Hg} 2+, \mathrm{CH} 3 \mathrm{Hg}+$, and $\mathrm{Cd} 2+$ towards mixtures of two biological thiols by HPLC-ICP-AES. J Inorg Biochem. 2011;105(3):375-81.

26. Rabenstein DL, Isab AA, Reid RS. A proton nuclear magnetic resonance study of the binding of methylmercury in human erythrocytes. Biochim Biophys Acta. 1982;720(1):53-64.

27. Meng B, Feng X, Qiu G, Anderson CW, Wang J, Zhao L. Localization and speciation of mercury in brown rice with implications for Pan-Asian public health. Environ Sci Technol. 2014;48(14):7974-81.

28. Lemes M, Wang F. Methylmercury speciation in fish muscle by HPLC-ICP-MS following enzymatic hydrolysis. J Anal At Spectrom. 2009;24(5):663-8

29. Thomas SA, Catty P, Hazemann JL, Michaud-Soret I, Gaillard JF. The role of cysteine and sulfide in the interplay between microbial $\mathrm{Hg}$ (ii) uptake and sulfur metabolism. Metallomics. 2019;11(7): 1219-29.

30. Carty A, Malone S, Nriagu J. The biogeochemistry of mercury in the environment, Edited by (1979) 433-479.

31. Leopold K, Foulkes M, Worsfold P. Methods for the determination and speciation of mercury in natural waters - a review. Anal Chim Acta. 2010;663(2):127-38.

32. Bjorn E, Larsson T, Lambertsson L, Skyllberg U, Frech W. Recent advances in mercury speciation analysis with focus on spectrometric methods and enriched stable isotope applications. Ambio. 2007;36(6):443-51

33. Harrington CF. The speciation of mercury and organomercury compounds by using high-performance liquid chromatography. TrACTrend Anal Chem. 2000;19(2):167-79.

34. Krupp EM, Milne BF, Mestrot A, Meharg AA, Feldmann J. Investigation into mercury bound to biothiols: structural identification using ESI-ion-trap MS and introduction of a method for their HPLC separation with simultaneous detection by ICP-MS and ESIMS. Anal Bioanal Chem. 2008;390(7):1753-64.

35. Bouchet S, Björn E. Analytical developments for the determination of monomethylmercury complexes with low molecular mass thiols by reverse phase liquid chromatography hyphenated to inductively coupled plasma mass spectrometry. J Chromatogr A. 2014;1339: 50-8.

36. Janssen SE, Schaefer JK, Barkay T, Reinfelder JR. Fractionation of mercury stable isotopes during microbial Methylmercury production by iron-and sulfate-reducing bacteria. Environ Sci Technol. 2016;50(15):8077-83.

37. Oasis Sample Extraction Products, Waters. https://www.waters. com/waters/en SE/Waters-Oasis-Sample-Extraction-SPEProducts/nav.htm?cid=513209\&locale=en SE.

Publisher's note Springer Nature remains neutral with regard to jurisdictional claims in published maps and institutional affiliations. 